\title{
Neuropeptides Profile and Increased Innervation in Becker's Nevus
}

\author{
Ji Seok Kim, Myeong Jin Park, Hye Young Kang, Seung Phil Hong, Byung Cheol Park, Myung Hwa Kim \\ Department of Dermatology, Dankook University College of Medicine, Cheonan, Korea
}

Background: Melanocytes are derived from neural crest, and various pigmentary disorders may accompany abnormalities in nerve system or develop following dermatome, suggesting that melanocyte and pigmentation may be closely related to neural factors. There are reports of Becker's nevus (BN) showing linear and segmental configuration, suggesting the association of $\mathrm{BN}$ with nerve system. However, there are no studies regarding the expression of neuropeptides in $\mathrm{BN}$. Objective: We investigated the expression of neuropeptides and innervation in BN. Methods: Polymerase chain reaction (PCR) array of 84 genes related to neuronal process was done. Among the genes with 10-fold or more increase in lesional, real-time PCR was performed for neuropeptide $Y$ (NPY), galanin, neurotensin (NTS) and their receptors skin compared to normal skin. IHC stain was done to look for the expression of NPY, galanin, NTS and their receptors and the distribution of protein gene products (PGP) 9.5 immunoreactive nerve fibers. Results: PCR array revealed that 16 out of 84 genes related to neuronal process were increased by 10-fold or more in lesional skin. In real-time PCR of NPY, galanin, NTS and their receptors, statistically significant increase of NPY1R $(p<0.05)$ and marginally significant increase of NPY2R, GAL2R, and NTS2R $(p<0.1)$ was verified in lesional skin. In immunohistochemistry, NPY, NPY1R

Received January 17, 2018, Revised October 13, 2018, Accepted for publication October 15, 2018

Corresponding author: Myung Hwa Kim, Department of Dermatology, Dankook University Hospital, 201 Manghyang-ro, Dongnam-gu, Cheonan 31116, Korea. Tel: 82-41-550-6486, Fax: 82-41-552-7541, E-mail: ivymyung@hanmail.net

ORCID: https://orcid.org/0000-0002-9072-201X

This is an Open Access article distributed under the terms of the Creative Commons Attribution Non-Commercial License (http://creativecommons. org/licenses/by-nc/4.0) which permits unrestricted non-commercial use, distribution, and reproduction in any medium, provided the original work is properly cited.

Copyright (c) The Korean Dermatological Association and The Korean Society for Investigative Dermatology
NPY2R, and NTS2R were highly expressed in lesional skin and increased PGP 9.5 immunoreactive linear nerve fibers were found in the epidermis of BN. Conclusion: NPY, galanin, NTS and their receptors and increased innervation may play a role in the pathogenesis of BN. (Ann Dermatol 31(2) $154 \sim 163,2019$ )

\section{-Keywords-}

Becker nevus, Galanin, Neuropeptide Y, Neurotensin, Protein gene product 9.5

\section{INTRODUCTION}

Becker's nevus (BN) was first described by Becker ${ }^{1}$ in 1949, with cases where unilateral hypertrichosis and hyperpigmentation occurred on upper back. BN clinically shows an irregular well defined brownish macular area, which is frequently associated with hypertrichosis and acneiform lesions. The pathogenesis of BN is not fully understood, and it has been reported to be related with sun-exposure and increased susceptibility and reaction to androgen hormone $^{2,3}$.

Melanocytes and peripheral nerve systems are all derived from neural crest, and various pigmentary disorders may accompany abnormalities in neural system or develop within specific dermatome, suggesting that melanocyte and hyperpigmentation may be closely related to neural factors ${ }^{4,5}$. It is known that nerve fibers which secrete neuropeptides are physically connected to melanocytes, and some neuropeptides are responsible for triggering proliferation of melanocytes ${ }^{6}$. There are also reports that increased number of cutaneous nerve endings have been found in pigmentary disorders such as café au lait macules and congenital giant pigmented nevus ${ }^{7,8}$. There are reports of melasma having increased expression of nerve growth factor 
and neural endopeptidases ${ }^{9}$.

Several case reports about $\mathrm{BN}$ showing linear and segmental configuration suggest a possibility of occurrence of $\mathrm{BN}$ in nerve distribution ${ }^{10,11}$. Furthermore, it has been reported recently that protein gene products (PGP) $9.5+$ nerve fibers were abundantly distributed in dermis $\mathrm{BN}$ compared with normal skin ${ }^{12}$.

From these perspective that neural factors may be closely related to epidermal pigmentation, we sought to verify factors related to neural process in the lesion of $\mathrm{BN}$ including neuropeptides and their receptors and look for possible relationship between these factors and epidermal hyperpigmentation of BN. Among the neuropeptides that can be found in human skin, neuropeptide $Y$ (NPY) is related to neural crest-derived tumors as well as blue, fusiform, halo nevi and melanoma ${ }^{13}$, and galanin was reported to be expressed in a greater degree in some cutaneous melanomas, which were strongly correlated with $\alpha-\mathrm{MSH}$ expression of the same tumors ${ }^{14}$. Neurotensin (NTS) stimulates human mast cell degranulation and activates mast cells, which is known to contribute epidermal hyperpigmentation in dermatofibroma, urticarial pigmentosa, postinflammatory hyperpigmentation ${ }^{15}$.

There are no previous reports regarding the role of neuropeptides and nerves in hyperpigmentary lesions of BN. In this study, we investigated whether a linkage may exist among nerve-derived factors such as neuropeptides, distribution of nerve endings, mast cells and hyperpigmentation in $\mathrm{BN}$.

\section{MATERIALS AND METHODS}

\section{Patients and samples}

Skin specimens used in polymerase chain reaction (PCR) array and real-time PCR were obtained from 3 patients, 41-year-old male, 49-year-old male, and 20-year-old male diagnosed as $\mathrm{BN}$ after informed consent of the experiment. The patients had no history of other medical problems. As for immunohistochemical (IHC) study, 3 lesional and 3 normal skin biopsy specimens using a 4-mm disposable punch were used to stain with antibodies associated with NPY, galanin, NTS and their receptors, and PGP 9.5. Normal skin samples were obtained from at least $10 \mathrm{~cm}$ from the lesion. This study was approved by Institutional Review Board at Dankook University Hospital (IRB no. 2013-08-002).

\section{PCR array}

$\mathrm{RT}^{2}$ Profiler ${ }^{\mathrm{TM}}$ PCR Arrays of "Human neurotrophin and receptors" (PAHS-031Z; Qiagen, Valencia, USA) was used in the study. It profiles the expression of 84 genes related to neuronal processes. Genes involved in normal function of the neuronal system and cytokines and receptors involved in neuronal signaling are contained on the array. Skin samples were obtained by biopsy of the lesions using a 4-mm disposable punch from three patients with $\mathrm{BN}$ and immediately frozen at $-80^{\circ} \mathrm{C}$. Total RNA was extracted Using RNeasy mini kit (Cat. No. 74104; Qiagen) from frozen tissue samples. The tissues were ground to powder under frozen conditions and lysed in the lysis buffer provided by Qiagen, Inc. and other steps were performed according to the manufacturer's protocol. Quality and quantity of RNA were determined using the NanoDrop 2000 (Thermo Scientific Inc., Wilmington, DE, USA). The RT reaction was performed with $1 \mu \mathrm{g}$ total RNA using the RT2 First-Strand Kit (Cat. No. 330401; Qiagen). Randomprimed cDNAs were processed for quantitative real-time reverse-transcriptase PCR of 84 genes involved in neuronal processes and 12 housekeeping genes, including internal controls, by using an $\mathrm{RT}^{2}$ Profiler PCR Array Kit $\left(\mathrm{RT}^{2}\right.$ Profiler PCR Array Human neurotrophin and receptors, PAHS-031Z; Qiagen) and an Eppendorf RealPlex ${ }^{2}$ Mastercycler PCR system. PCR products were quantified by measuring SYBR Green (Invitrogen, Carlsbad, CA, USA) fluorescent dye incorporation with ROX dye reference using $\mathrm{RT}^{2}$ SYBR Green ROX qPCR Mastermix (Cat. No. 330623; Qiagen). Using an integrated web-based software package for the PCR Array System, the $\Delta \Delta \mathrm{C}_{\mathrm{t}}$-based fold-change calculations from the uploaded raw threshold cycle data were obtained.

\section{Real-time PCR}

Real-time PCR arrays were performed by using products of SABiosciences. cDNAs were synthesized using QuantiTect Rev. Transcription Kit (Cat. No. 205311; Qiagen) according to its protocol. The reaction was performed at $42^{\circ} \mathrm{C}$ for 15 minutes and then stopped immediately by heating at $95^{\circ} \mathrm{C}$ for 5 minutes. Amplification, data acquisition, and the melting curve were carried out by the $A B I 7900$ Real Time PCR system (Applied Biosystems, Foster City, CA, USA). The PCR cycling program was set as follows: stage 1: $95^{\circ} \mathrm{C}$ for 5 minutes, stage 2 : $95^{\circ} \mathrm{C}$ for 10 seconds followed by $60^{\circ} \mathrm{C}$ for 30 seconds repeated for 40 cycles, and stage 3: $95^{\circ} \mathrm{C}$ for 15 seconds, $60^{\circ} \mathrm{C}$ for 15 seconds and $95^{\circ} \mathrm{C}$ for 15 seconds. The cycle threshold $(\mathrm{Ct})$ and melting curve of each gene were automatically established and recorded by the software. The delta $\mathrm{Ct}(\Delta \mathrm{Ct})$ method was used for PCR array data analysis. The primer sequences for real-time PCR is described in Table 1.

\section{Immunohistochemistry}

Paraffin-embedded sections (4 $\mu \mathrm{m})$ of BN lesion and nor- 
Table 1. Real-time polymerase chain reaction primer sequences used in this study

\begin{tabular}{|c|c|c|}
\hline $\begin{array}{l}\text { Gene } \\
\text { name }\end{array}$ & $\begin{array}{l}\text { Reference } \\
\text { sequence }\end{array}$ & Sequence $\left(5^{\prime} \rightarrow 3^{\prime}\right)$ \\
\hline NPY & $\mathrm{NM}_{0}$ & $\begin{array}{l}\text { Forward GAACTCGGCTTGAAGACCCT } \\
\text { Reverse GGCTGCATGCATTGGTAGGA }\end{array}$ \\
\hline NPY1R & $\begin{array}{l}\mathrm{NM}_{-} \\
000909.5\end{array}$ & $\begin{array}{l}\text { Forward AATGCTTCCCCGAGGTGTG } \\
\text { Reverse ACGCCTCCTTAAAGCCGAAC }\end{array}$ \\
\hline NPY2R & $\mathrm{NM}^{\mathrm{N}}$ & $\begin{array}{l}\text { Forward CAAAACTTCTCCTCСАGTCCСC } \\
\text { Reverse AAGGTGGGAGGATCAGAGATGG }\end{array}$ \\
\hline GAL & $\mathrm{NM}^{015973}$ & $\begin{array}{l}\text { Forward AACCAGGAAGCTTTGACAGGT } \\
\text { Reverse CCGCTCGATGTCTTCTGAGG }\end{array}$ \\
\hline GAL1R & $\begin{array}{l}\mathrm{NM} \\
001480.3\end{array}$ & $\begin{array}{l}\text { Forward GACACCCCACCATCAACCAA } \\
\text { Reverse AACAAGTTGCAGCATCGCTT }\end{array}$ \\
\hline GAL2R & $\begin{array}{l}\mathrm{NM}_{-} \\
003857.3\end{array}$ & $\begin{array}{l}\text { Forward AGGTGACACGCATGATCCTC } \\
\text { Reverse GAGTTGGCGTAGGAGACCAG }\end{array}$ \\
\hline NTS & $\mathrm{NM}_{-}$ & $\begin{array}{l}\text { Forward GCAGGGCTTITCAACACTGG } \\
\text { Reverse TCATACAGCTGCCGTTTCAGA }\end{array}$ \\
\hline NTS1R & $\mathrm{NM}^{0-}$ & $\begin{array}{l}\text { Forward CTCGGATGAGCAGTGGACTC } \\
\text { Reverse AGTTGGCAGAGACGAGGTTG }\end{array}$ \\
\hline NTS2R & $\mathrm{NM}_{012344.3}$ & $\begin{array}{l}\text { Forward ACCTGATGACGCGTGGACTG } \\
\text { Reverse CTCCACACAGGGAGCTGACG }\end{array}$ \\
\hline
\end{tabular}

mal skin of the same anatomical site were selected, and $\mathrm{IHCl}$ analysis was performed using the commercial kit $\mathrm{LSAB}^{\circledR}+$ /horseradish peroxidase (HRP) System (Cat. No. K0679; Dako, Carpinteria, USA). Briefly, after deparaffinization of samples and antigen retrieval, the sections were stained with primary antibodies against NPY (Cat. No. ab112473, 1:50 dilution; Abcam, Novusbio, Santa Cruz, LS Bio, Usbiological, Millipore), NPYR (Cat. No. NBPI59008, 1:5,000 dilution; Novusbio), NPYR2 (Cat. No. NB10056480, 1:5,000 dilution; Novusbio) or biotin-conjugated isotype control IgGs and incubated for overnight at $4{ }^{\circ} \mathrm{C}$, and antibodies against GAL (Cat. No. sc-166431, 1:2,000 dilution; Santa Cruz), GALR1 (Cat. No. NLS4013, 1:1,000 dilution; Novusbio), GALR2 (Cat no. LS-B4081, 1:500 dilution; LS Bio) were used for staining and incubated for 1 hour at room temperature. NTS (Cat. No. 151977, 1:500 dilution; Usbiological), NTS1R (Cat. No. ab75555, 1:1,000 dilution; Abcam), NTS2R (Cat. No. NLS1269 1:2,000 dilution; Novusbio), PGP 9.5 (Cat. No. AB176-I 1:1,000 dilution; Millipore) Later, the slides were stained with biotinylated anti-rabbit, mouse, and goat immunoglobulin and streptavidin-HRP complex for 30 minutes each and were washed with phosphate-buffered saline. After staining with AEC (Peroxidase substrate kit, SK-4200; Vector Laboratories, Burlingame, CA, USA) as a substrate and dying with Mayer's hematoxylin for 2 minutes, the slides were covered with cover glass and then examined by using light microscope.
Table 2. Results of polymerase chain reaction array of "Human neurotrophin and receptors"

\begin{tabular}{lr}
\hline Gene symbol & Fold \\
\hline MC2R & 50.95 \\
NPFFR2 & 32.17 \\
NTF3 & 24.73 \\
GRPR & 24.03 \\
NR112 & 22.96 \\
NPY & 22.58 \\
NTSR1 & 21.48 \\
NPY2R & 18.79 \\
NRG1 & 18.07 \\
GALR2 & 16.66 \\
HCRT & 16.66 \\
MT3 & 16.66 \\
NTRK1 & 16.66 \\
IL10 & 13.64 \\
GALR1 & 12.56 \\
CX3CR1 & 11.99 \\
PTGER2 & 8.68 \\
GFRA2 & 6.77 \\
CRH & 6.77 \\
CRHR2 & 6.43 \\
NGF & 6.02 \\
UCN & 5.12 \\
IL1B & 5.05 \\
NTF4 & 4.22 \\
CBLN1 & 3.88 \\
NRG4 & 3.73 \\
PNOC & 3.73 \\
GFRA1 & 3.58 \\
FGF2 & 3.56 \\
CRHR1 & 3.50 \\
PSPN & 3.36 \\
LIF & 3.36 \\
ARTN & 3.34 \\
ADCYAP1R & 3.09 \\
\hline &
\end{tabular}

\section{Statistical analysis}

A paired t-test was employed to determine differences in the expression levels of neuropeptides between lesional and normal skin. Data were valued with in a confidence interval of $95 \%$. A $p$-value of less than 0.05 was considered statistically significantly different $(p<0.05)$. A $p$-value of less than 0.1 was considered marginally statistically significantly different $(p<0.1)$.

\section{RESULTS}

There were increased level of certain neuropeptides' mRNA expression in lesional skin on PCR array

Out of total 84 gene symbols, 34 genes were increased by 
3-fold or more in lesional skin compared to normal skin (Table 2). Among them, 16 genes with 10-fold or more increase are as follows by order of fold increases (Fig. 1). Although there are many genes which have a link to melanogenesis through literature research like $M C 2 R$, we chose

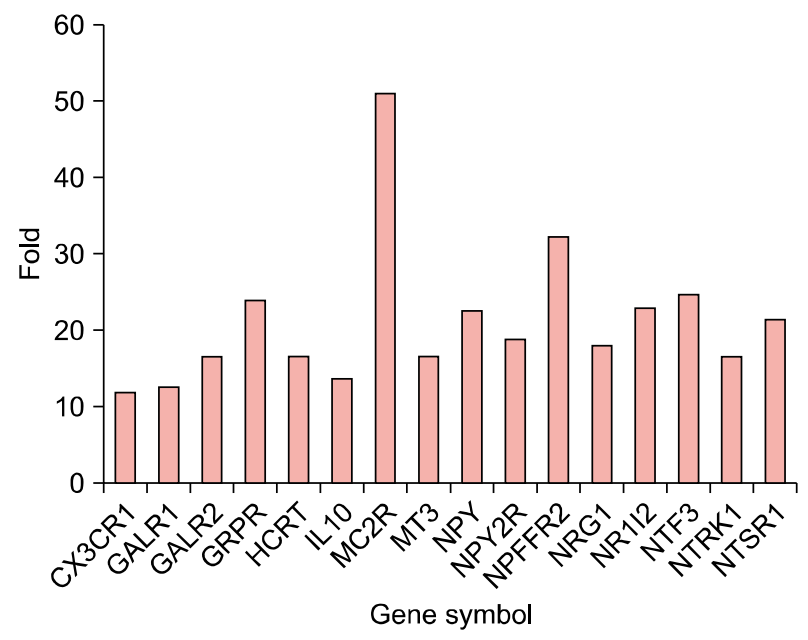

Fig. 1. Results of polymerase chain reaction array of "Human neurotrophin and receptors." Sixteen genes among 84 genes were increased by 10 -fold or more when compared to normal skin.

A

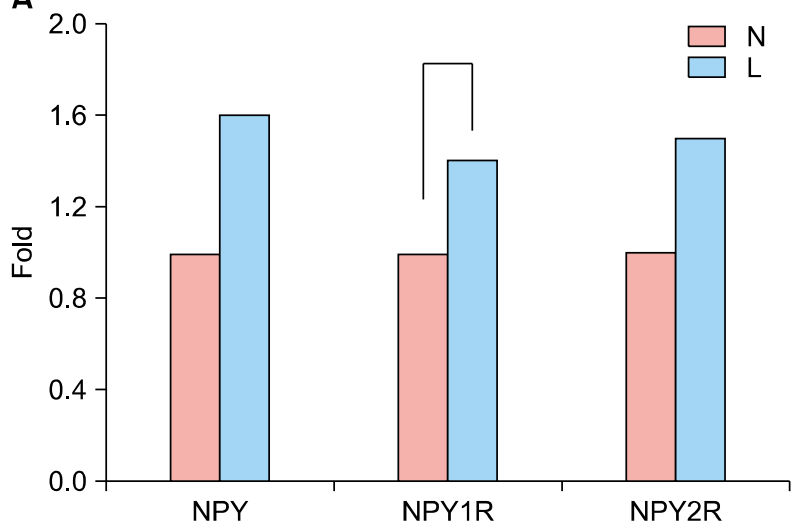

C

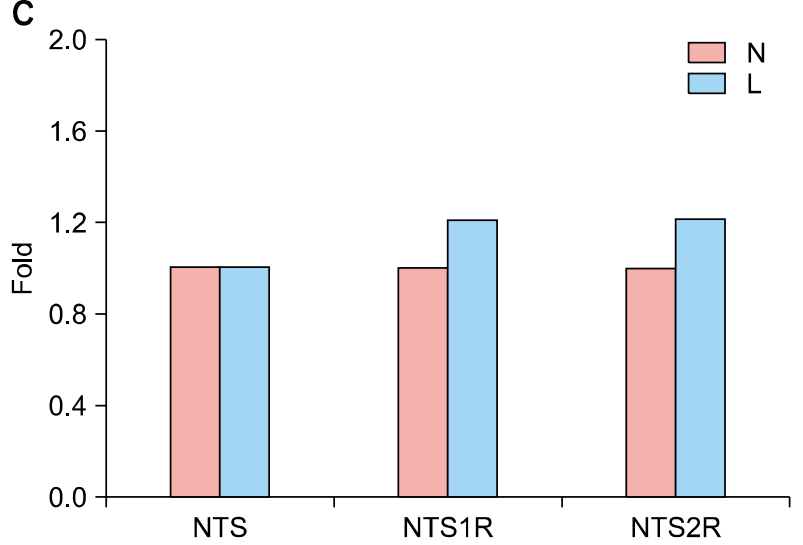

3 easily approachable genes in our laboratory among those 16 genes.

Significant difference in level of NPY, galanin, NTS and their receptors' mRNA expression between lesional and normal skin was confirmed by real-time PCR

Upon comparing the level between lesional and normal skin, the mRNA levels of NPY, NPY1R and NPY2R were increased by $1.6,1.4$, and 1.5 fold, respectively in lesional skin (Fig. 2A). The mRNA levels of galanin, GAL1R and GAL2R were increased by $1.0,1.5$, and 2.1 fold, respectively in lesional skin when compared to normal skin (Fig. 2B). And, the mRNA levels of NTS, NTS1R and NTS2R were increased by $1.0,1.2$, and 1.2 fold respectively in lesional skin compared to normal skin (Fig. 2C).

In general, statistically significant increase of NPY1R $(p<$ 0.05 ) and marginally significant increase of NPY2R, GAL2R, and NTS2R $(p=0.061, p=0.089, p=0.066)$ was verified in lesional skin compared to normal skin.

Distribution of neuropeptides and their receptors on lesional and normal skin showed difference in immunohistochemistry

NPY, NPY1R and NPY2R were higher degree of expres-

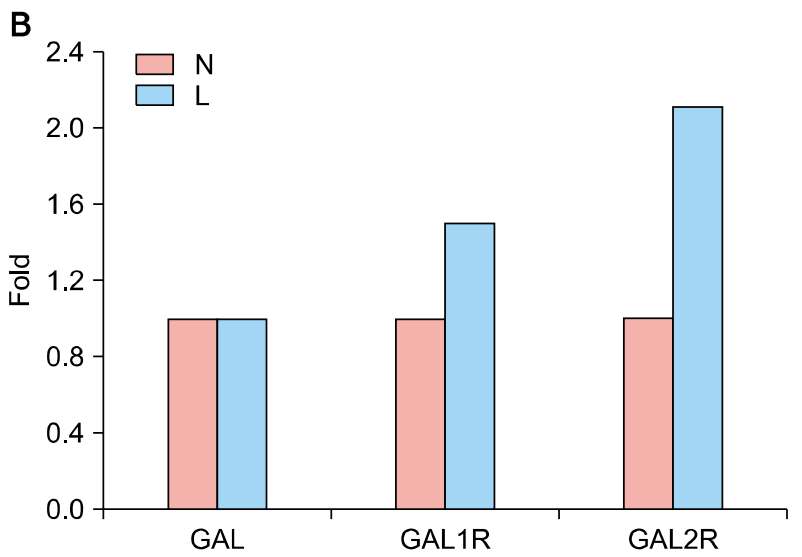

Fig. 2. (A) Results of real-time polymerase chain reaction (PCR) of neuropeptide Y (NPY) and its receptors. Among all ligands and receptors, NPYR1 was statistically significantly increased in lesional skin when compared to normal skin $(p=0.042)$. (B) Results of real-time PCR of galanin (GAL) and its receptors. Among all ligands and receptors. (C). Results of real-time PCR of neurotensin (NTS) and its receptors. Among all ligands and receptors. N: normal, L: lesion. 

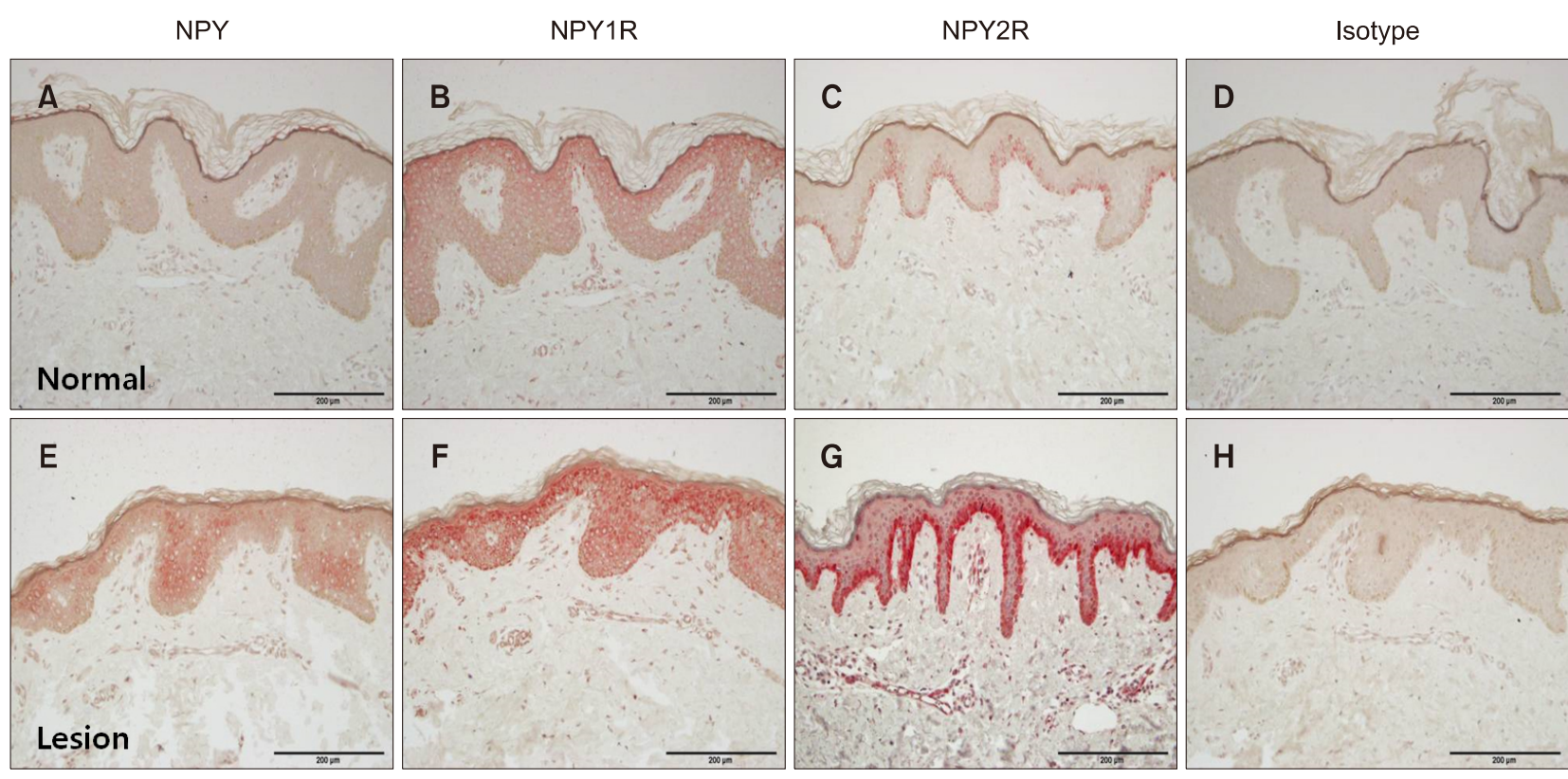

Fig. 3. Immunohistochemistry showing difference in expression of neuropeptide $Y(N P Y)$ and its receptors between lesional and normal skin. NPY, NPY1R and NPY2R were all expressed in epidermis and dermis of lesional $(E \sim G)$, and normal skin $(A \sim C)$, with higher degree of expression when compared to normal skin. NPY was expressed in spinous layer, NPY1R in whole layer of epidermis, and NPY2R in basal layer. (D), (H) Isotype control. Scale bar $=200 \mu \mathrm{m}$.

GAL

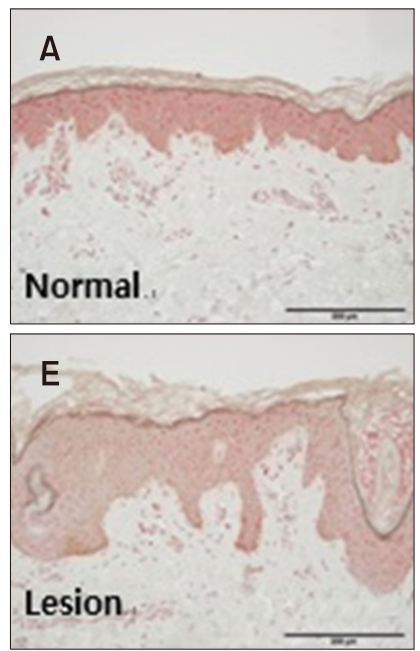

GAL1R
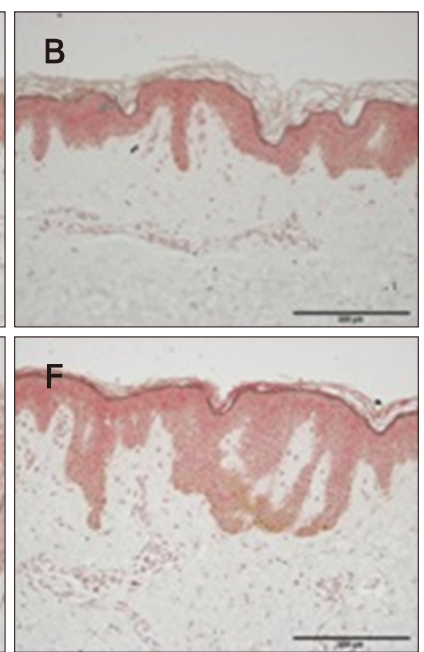

GAL2R

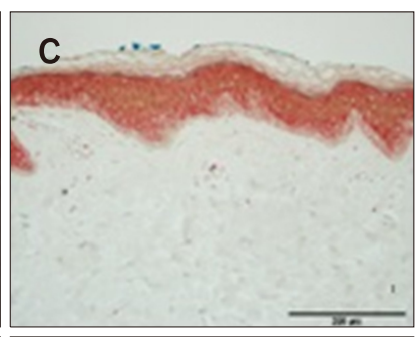

G

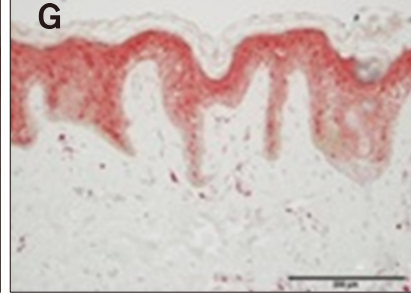

Isotype

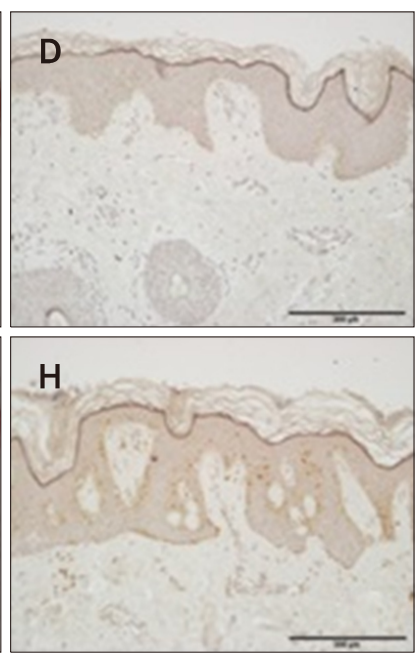

Fig. 4. Immunohistochemistry showing difference in expression of galanin (GAL) and its receptors between lesional and normal skin. Galanin, GAL1R and GAL2R were all expressed in epidermis and dermis of lesional $(E \sim G)$, and normal skin $(A \sim C)$, with similar degree of expression when compared to normal skin. GAL and GAL1R were expressed in whole layer of epidermis, and GAL2R in spinous layer. (D), (H) Isotype control. Scale bar $=200 \mu \mathrm{m}$.

sion in epidermis and dermis of lesional skin (Fig. 3E $\sim \mathrm{G})$ comparing to normal skin (Fig. $3 \mathrm{~A} \sim \mathrm{C}$ ), with NPY being stained in the spinous layer (Fig. 3E), NPY1R being stained throughout the whole layer of epidermis (Fig. 3F) while NPY2R being stained in the basal layer of epidermis (Fig. 3G). Galanin, GAL1R and GAL2R were all expressed in epidermis and dermis of lesional (Fig. $4 \mathrm{E} \sim \mathrm{G}$ ) and normal skin
(Fig. 4A $\sim \mathrm{C}$ ), with similar degree of expression when compared to normal skin. GAL and GAL $1 R$ were expressed in whole layer of epidermis (Fig. 4E, F), and GAL2R in spinous layer (Fig. 4G).

NTS and NTS1R were expressed in epidermis and dermis of lesional (Fig. 5E, F), and normal skin (Fig. 5A, B), similar degree of expression when compared to normal skin. 

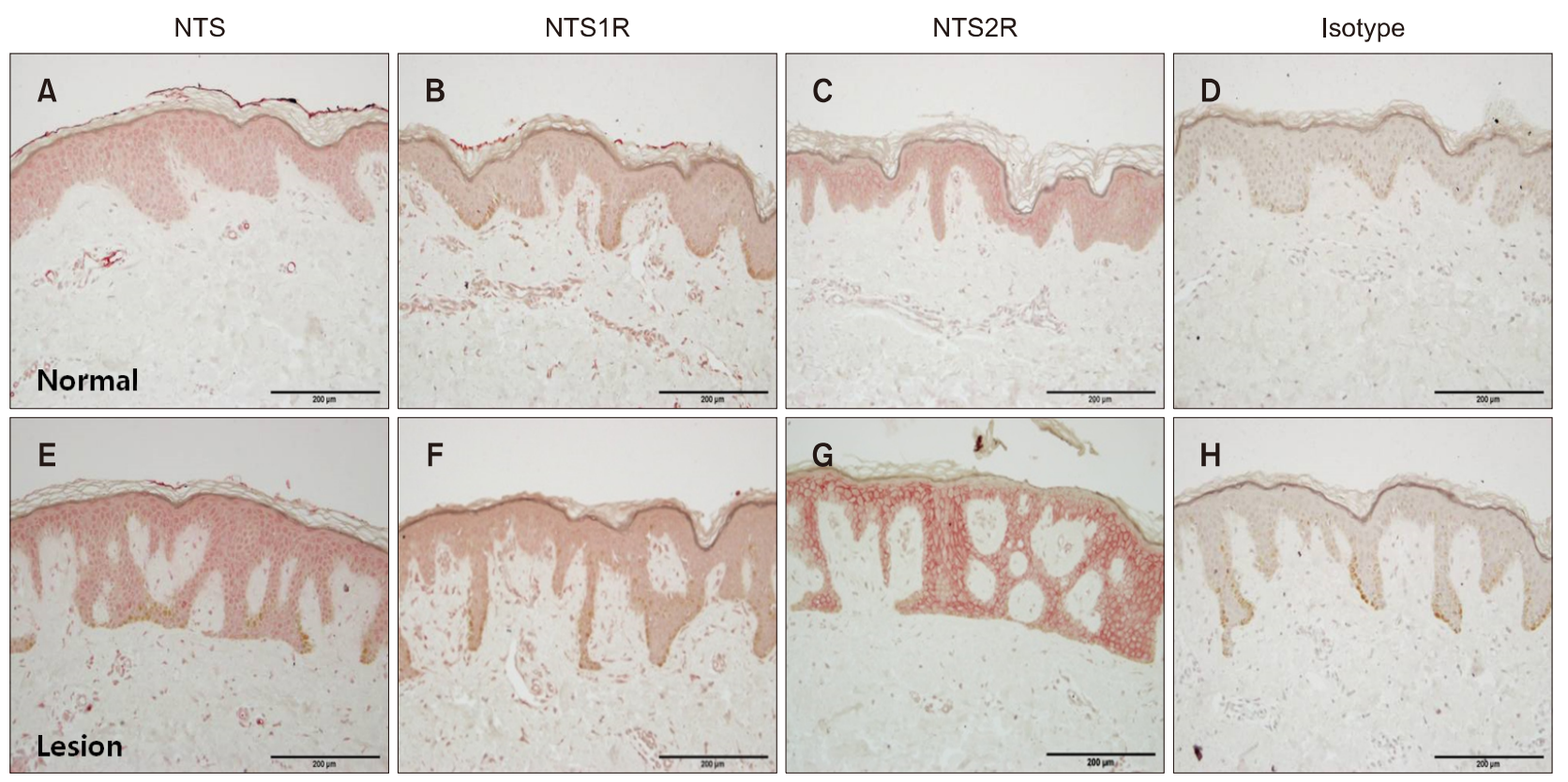

Fig. 5. Immunohistochemistry showing difference in in expression of neurotensin (NTS) and its receptors between lesional and normal skin. NTS and NTS1R were expressed in epidermis and dermis of lesional $(E \sim G)$, and normal skin $(A \sim C)$, similar degree of expression when compared to normal skin. NTS2R was expressed with higher degree of expression in lesional skin when compared to normal skin. NTS and its receptors were expressed in whole layer of epidermis. (D), (H) Isotype control. Scale bar $=200 \mu \mathrm{m}$.

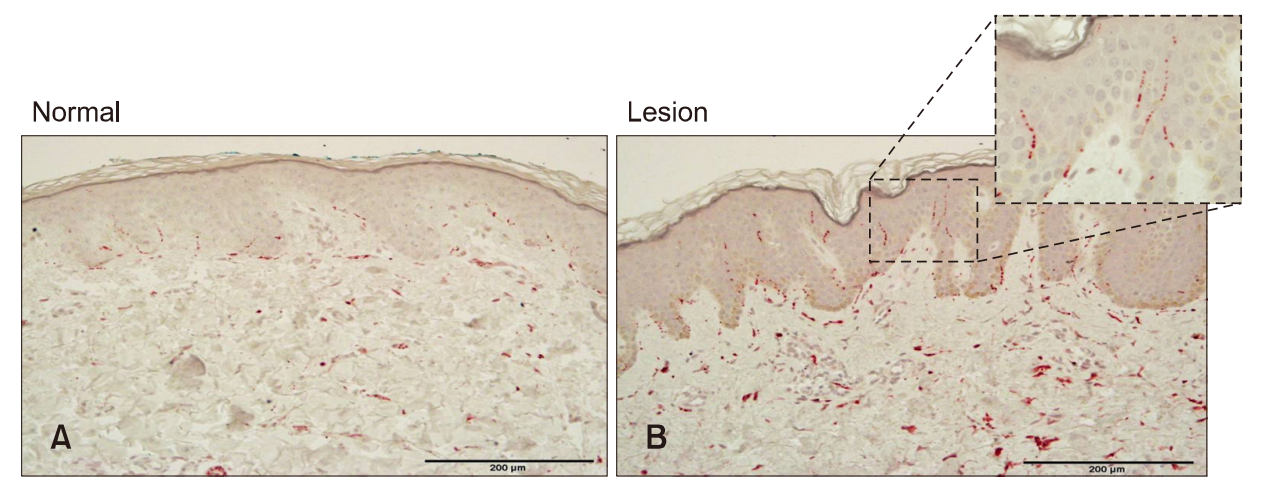

Fig. 6. (A, B) Immunohistochemistry showing difference in protein gene products (PGP) 9.5 immunoreactive nerve fibers between lesional and normal skin. PGP 9.5 immunoreactive nerve fibers were found in the epidermis and dermis, revealing the increased innervations in lesional skin when compared to normal skin. Linear nerve fibers were increased in lesional epidermis (B, inlet). Scale bar $=200 \mu \mathrm{m}$.
NTS2R was expressed with higher degree of expression in lesional skin (Fig. 5G) when compared to normal skin (Fig. $5 C$ ). NTS and its receptors were expressed in whole layer of epidermis.

\section{Distribution of PGP 9.5 immunoreactive nerve fibers on lesional and normal skin showed difference in immunohistochemistry}

PGP 9.5 immunoreactive nerve fibers were found in the epidermis and dermis, revealing the increased innervations in lesional skin when compared to normal skin. Linear nerve fibers were increased in lesional epidermis (Fig. 6A, B).

\section{Increased mast cells in lesional skin}

By toluidine blue stain, an increased number of mast cells was found in perivascular area of lesional skin when compared to normal skin (Fig. 7).

\section{DISCUSSION}

The epidermal changes of $\mathrm{BN}$ are variable, although it usually shows hyperkeratosis, subtle acanthosis, papillomatosis, flattened rete ridge elongation and basal layer hyperpigmentation. The hyperpigmentation of $\mathrm{BN}$ can be treated with various kinds of laser therapy targeting melanocyte and/or melanin such as Q-switched ruby (694 nm), alexandrite and frequency-doubled Nd:YAG (532 nm), however, recurrence is common ${ }^{16,17}$. More invasive treatment include mechanical abrasion, ablative laser treatment, cryotherapy, surgery and these therapies have been 


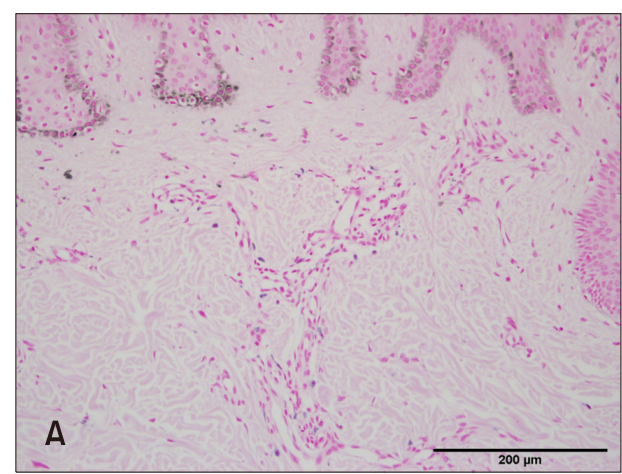

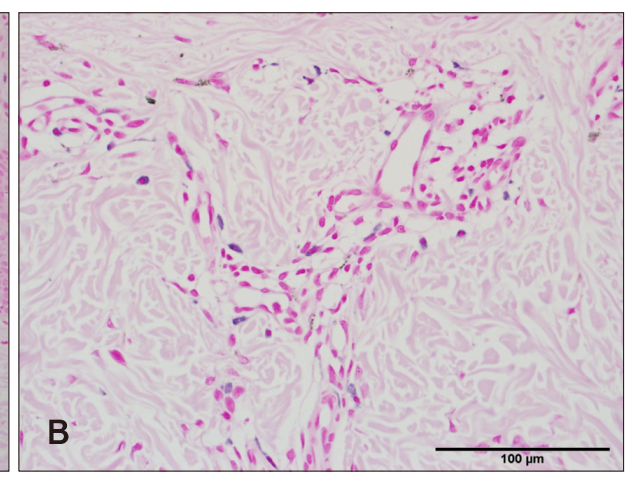

Fig. 7. Toluidine blue stain showing increased number of mast cells in perivascular area of lesional skin. (A) Scale bar $=200 \mu \mathrm{m}$, (B) scale bar $=100 \mu \mathrm{m}$. either unsuccessful or have resulted in scarring. However, the mechanism behind the pathogenesis of the epidermal hyperpigmentation and the treatment failure of $\mathrm{BN}$ remains to be clarified.

It has been linked various pigmentary disorders with neuronal process such as neurofibromatosis, melanocytic nevi, melasma, vitiligo, etc. ${ }^{9,18-22}$. Several cases about BN showing linear and segmental configuration suggest a possibility of occurrence of $\mathrm{BN}$ in nerve distribution ${ }^{10,11}$. Also, there are reports of $\mathrm{BN}$ in a patient with neurofibromatosis $^{23,24}$. Recently, Sheng et al. ${ }^{12}$ reported that PGP $9.5+$ nerve fibers were abundantly distributed in dermis. They found that dermal nerve fiber length was higher in the nerve plexus and arrector pili muscles and around eccrine ducts and that dermal nerve fiber length was higher in lesional and perilesional skin compared with normal skin. Collectively, these previous reports suggest that nerve or neural factors might influence the epidermal hyperpigmentation of $\mathrm{BN}$. However, there are no previous reports about the neuropeptides and nerve in epidermal hyperpigmentary lesions of $\mathrm{BN}$. Therefore, we hypothesized that a linkage may exist between nerve-derived factors such as neuropeptides and melanocytes, and that they may play an important role in the mechanism of hyperpigmentation in $\mathrm{BN}$ or recurrence after melanocyte-targeting laser therapy or ablative treatment.

Using lesional and normal tissue specimen from patients with $\mathrm{BN}$, we performed a PCR array to figure out increased neural components, and have found that several neuropeptides including NPY, galanin, NTS and its receptors were significantly increased in lesional skin of $\mathrm{BN}$ when compared to normal skin.

NPY is a 36 amino-acid long peptide characterized by many tyrosine residues ${ }^{25}$. It is mainly produced by the neurons of different brain locations and is stored and released in sympathetic peripheral nerve endings regulating various organ systems ${ }^{26}$. Other than physiologic functions, NPY can also act as growth and angiogenic factor and are related to neural crest-derived tumors as well as blue, fusi- form, halo nevi and melanoma. It has been reported that NPY mediates invasiveness of tumors by modulating angiogenesis, apoptosis, cell adhesion and motility. Furthermore, a positive relationship between the expression of $\alpha-\mathrm{MSH}$ and NPY was found in melanocytic lesions ${ }^{13}$. NPY was also reported to regulate the secretory activity of melanin-containing cells in Xenopus laevis ${ }^{27}$. From the reports we can predict that neuropeptides may not regulate synthesis of melanin within melanocytes but rather affect melanosomal transfer to surrounding keratinocytes. It is known in previous reports that NPY is known to be one of the major neuronal peptides found in human $\mathrm{skin}^{28}$. The presence of NPY receptor that couples to inhibitory G protein was shown in keratinocytes, and the activity of the receptor was demonstrated to be downregulated by glucocorticoid treatment in keratinocytes ${ }^{29}$.

Our study revealed statistically significant increase of NPY1R $(p<0.05)$ and marginally significant increase of NPY2R $(p=0.061)$ level in lesional skin compared to normal skin through real-time PCR. Furthermore, immunohistochemistry showed that NPY, NPY1R, and NPY2R were expressed with higher degree of expression in lesional skin when compared to normal skin. From the fact that NPY, NPY1R and NPY2R expression were significantly increased in lesional skin, it is possible that NPY and its receptors may be involved in epidermal hyperpigmentation of $\mathrm{BN}$ by interacting with hormones such as $\alpha-\mathrm{MSH}$ or stimulating melanin transfer.

Galanin is a neuropeptide with wide-range of effects within endocrine and nervous system. It was reported that galanin is expressed in a greater degree in some cutaneous melanomas, which were strongly correlated with $\alpha-\mathrm{MSH}$ expression of the same tumors ${ }^{14}$. It appears that galanin expression in pituitary adenomas is linked to expression of ACTH which is a neuropeptide derived from proopiomelanocortin like $\alpha-\mathrm{MSH}^{30,31}$. Previous reports revealed that galanin is expressed in keratinocytes, eccrine glands, and around vessels of human skin, suggesting its role other than those attributed to the nervous system ${ }^{32}$. Interestingly 
in one study, galanin mRNA level was downregulated in melanocytes after being treated with Q-switched Ruby laser, suggesting that galanin is expressed in human melanocytes $^{33}$. Furthermore, through the report of expression of both galanin and $\alpha$-MSH in melanoma, the interaction between galanin and $\alpha-\mathrm{MSH}$ may contribute to proliferation of melanocyte ${ }^{14}$. Other studies reported that galanin receptor mRNA expression was found in both cultured primary and transformed keratinocytes ${ }^{34}$.

Real-time PCR showed marginally significant increase of GAL2R level in lesional skin compared to normal skin $(p=0.089)$. Galanin, GAL1R and GAL2R were all expressed in lesional (Fig. 5E $\sim \mathrm{G}$ ) with similar degree of expression when compared to normal skin in IHC stain. Since the effect of galanin and its receptors in human skin is not well established so far, their role in pathogenesis and recurrence of $\mathrm{BN}$ is not clear. According to one report, it has been told that increased levels of galanin-like immunoreactivity and galanin mRNA could be found in cells of inflamed dermis and epidermis, and that galanin or galanin-like peptide is related in inflammatory response ${ }^{35}$. Consistently, our study showed that galanin and its receptors were expressed in epidermis and dermis of, and from these findings, it can be inferred that inflammatory process after laser therapy may increase the expression of galanin and/or its receptor resulting the melanocyte proliferation via interaction with $\alpha-\mathrm{MSH}$.

NTS is a single polypeptide chain containing 13 amino acid residues, which works as a neuromodulator in the central nervous system, and as an endocrine agent in the periphery $^{36,37}$. NTS1R is commonly high expressed in melanoma cells, but low expressed in normal immortalized human keratinocyte line HaCaT. SR48692, NTSR1 inhibitor, not only reduced cell proliferation and self-renewal potential in vitro, but also inhibited the tumor growth derived from A375 melanoma cells in NOD/SCID mice in vivo. The peptides corticotropin-releasing hormone $(\mathrm{CRH})$ and NTS have synergistic action stimulating mast cells and NTS triggered human mast cell degranulation and significantly augmented $\mathrm{CRH}$-induced vascular endothelial growth factor release ${ }^{38,39}$. Real-time PCR showed that NTS2R were verified marginally significant increase of NTS2R $(p=0.066)$ in lesional skin compared to normal skin. Immunohistochemistry showed consistently that NTS2R was expressed with higher degree of expression in lesional skin when compared to normal skin. Toluidine blue stain revealed an increased number of mast cells in perivascular area of lesional skin when compared to normal skin. These data support that NTS and its receptors might contribute to melanocyte proliferation and melanogenesis in $\mathrm{BN}$ directly or indirectly by stimulating mast cell degranu- lation.

Furthermore, immunochemical stain revealed that PGP 9.5 immunoreactive nerve fibers were found in the epidermis and dermis, revealing the increased innervations in lesional skin when compared to normal skin. Combined with the previous report showing PGP $9.5+$ nerve fibers were abundantly distributed in dermis of $\mathrm{BN}$ and dermal nerve fiber length was higher in lesional and perilesional skin compared with normal skin, increased innervation also might be an important to the way in which we understand the pathogenesis of $\mathrm{BN}$.

From the above mentioned role of each neuropeptides, we may hypothesize the way they could be related to hyperpigmentation of BN. Firstly, they may have an effect on hyperpigmentation along with the interaction of increase in $\alpha$-MSH level. It is well established that elevation in $\mathrm{MSH}$ levels may potentiate tyrosinase activity and stimulate melanogenesis of human $\operatorname{skin}^{40}$. Therefore, since high expression of NPY and galanin is related to the expression of $\alpha-\mathrm{MSH}$, it may ultimately result in hyperpigmentation in $\mathrm{BN}$ lesions through a set of responses mediated by $\alpha-\mathrm{MSH}$ or together with neuropeptides. Secondly, the pigmentation may be caused by inflammatory sequences. NPY and galanin are reported to have role in inflammation, for example, NPY stimulates mast cell degranulation and histamine-release $^{41}$. It has been reported that inflammatory mediators may increase activity of tyrosinase within melanocytes, which increases melanin production and transfer of melanosomes to keratinocytes ${ }^{42}$. In general, neuropeptides play an important role in regulating the synthesis and secretion of cytokines including interleukin (IL)-1, IL-2, IL-4, IL-6, and tumor necrosis factor- $\alpha^{43,44}$. Thus it is possible to speculate that neuropeptides are capable of modulating and interacting with melanocyte immune function during cutaneous inflammation. The limitation of our study includes the fact that the experiment included small number of samples, and the study did not clarify the functional aspect of NPY, galanin, and NTS including their role and effect on proliferation, migration, survival and melanogenesis of melanocytes. Our study was focused on comparing the expression level of genes related to neuronal process such as neuropeptides in both lesional and normal skin of patients with $\mathrm{BN}$, confirming that the expression of neuropeptides including NPY, galanin, and NPY are increased in BN. This result has an important value since it provides a clue that neurologic association should be considered when studying the pathogenesis of epidermal hyperpigmentary disorders. Further studies may be required for precise investigation on roles of these neuropeptides and search for other possible mediators in the pathogenesis of $\mathrm{BN}$. 
In conclusion, we hereby propose that NPY, galanin, NTS, their receptors and increased innervation may play a role in the pathogenesis of BN. Furthermore, these neuropeptides and increased innervation might be the possible factors inducing recurrence of $\mathrm{BN}$ treated by epidermal ablation and melanocyte or melanin targeted laser therapy. There are many limitations, but we think the results of this study will be valuable as a preliminary data associated with $\mathrm{BN}$ and neuropeptides.

\section{CONFLICTS OF INTEREST}

The authors have nothing to disclose.

\section{ORCID}

Ji Seok Kim, https://orcid.org/0000-0003-2385-9275

Myeong Jin Park, https://orcid.org/0000-0002-5160-7932

Hye Young Kang, https://orcid.org/0000-0002-9253-1540

Seung Phil Hong, https://orcid.org/0000-0002-0684-498X

Byung Cheol Park, https://orcid.org/0000-0002-5449-8313

Myung Hwa Kim, https://orcid.org/0000-0002-9072-201X

\section{REFERENCES}

1. Becker SW. Concurrent melanosis and hypertrichosis in distribution of nevus unius lateris. Arch Derm Syphilol 1949;60:155-160.

2. Glinick SE, Alper JC, Bogaars H, Brown JA. Becker's melanosis: associated abnormalities. J Am Acad Dermatol 1983; 9:509-514.

3. Person JR, Longcope C. Becker's nevus: an androgenmediated hyperplasia with increased androgen receptors. J Am Acad Dermatol 1984;10:235-238.

4. Stanford DG, Georgouras KE. Dermal melanocytosis: a clinical spectrum. Australas J Dermatol 1996;37:19-25.

5. Zvulunov A, Esterly NB. Neurocutaneous syndromes associated with pigmentary skin lesions. J Am Acad Dermatol 1995;32:915-935; quiz 936-937.

6. Hara M, Toyoda M, Yaar M, Bhawan J, Avila EM, Penner $\mathbb{R}$, et al. Innervation of melanocytes in human skin. J Exp Med 1996;184:1385-1395.

7. Bousema MT, Vuzevski V, Oranje A, Heule F, Stolz E, van Joost T. Non-von Recklinghausen's neurofibromatosis resembling a giant pigmented nevus. J Am Acad Dermatol 1989;20:358-362.

8. Zvulunov A, Metzker A. Neurofibromatosis versus giant pigmented nevus. J Am Acad Dermatol 1990;23:956-957.

9. Bak H, Lee HJ, Chang SE, Choi JH, Kim MN, Kim BJ. Increased expression of nerve growth factor receptor and neural endopeptidase in the lesional skin of melasma. Dermatol Surg 2009;35:1244-1250.

10. Pahwa P, Sethuraman G. Segmental Becker's nevi with mucosal involvement. Pediatr Dermatol 2012;29:670-671.
11. Ro YS, Ko JY. Linear congenital Becker nevus. Cutis 2005; 75:122-124.

12. Sheng P, Cheng YL, Cai CC, Guo WJ, Zhou Y, Shi G, et al. Clinicopathological features and immunohistochemical alterations of keratinocyte proliferation, melanocyte density, smooth muscle hyperplasia and nerve fiber distribution in Becker's nevus. Ann Dermatol 2016;28:697-703.

13. Gilaberte Y, Roca MJ, Garcia-Prats MD, Coscojuela C, Arbues MD, Vera-Alvarez JJ. Neuropeptide $Y$ expression in cutaneous melanoma. J Am Acad Dermatol 2012;66:e201e208.

14. Gilaberte Y, Vera J, Coscojuela C, Roca MJ, Parrado C, González S. [Expression of galanin in melanocytic tumors]. Actas Dermosifiliogr 2007;98:24-34. Spanish.

15. Tomita Y, Maeda K, Tagami H. Mechanisms for hyperpigmentation in postinflammatory pigmentation, urticaria pigmentosa and sunburn. Dermatologica 1989;179 Suppl 1:4953.

16. Nelson JS, Applebaum J. Treatment of superficial cutaneous pigmented lesions by melanin-specific selective photothermolysis using the Q-switched ruby laser. Ann Plast Surg 1992;29:231-237.

17. Goldberg DJ. Benign pigmented lesions of the skin. Treatment with the Q-switched ruby laser. J Dermatol Surg Oncol 1993; 19:376-379.

18. Chapel TA, Tavafoghi V, Mehregan AH, Gagliardi C. Becker's melanosis: an organoid hamartoma. Cutis 1981;27:405406, 410, 415.

19. Metin A, Tuncay I, Uğraş S. About the paper "Elephantiasis neuromatosa and Becker's melanosis" (J Dermatol, 26: 396-398, 1999). J Dermatol 2001;28:112-113.

20. Hara M, Kumasaka K, Tomita Y, Tagami H. Unilateral dermatomal pigmentary dermatosis: a variant dyschromatosis? J Am Acad Dermatol 1992;27:763-764.

21. Bröcker EB, Magiera $H$, Herlyn M. Nerve growth and expression of receptors for nerve growth factor in tumors of melanocyte origin. J Invest Dermatol 1991;96:662-665.

22. Lazarova R, Hristakieva E, Lazarov N, Shani J. Vitiligorelated neuropeptides in nerve fibers of the skin. Arch Physiol Biochem 2000;108:262-267.

23. Kim SY, Kim MY, Kang H, Kim HO, Park YM. Becker's naevus in a patient with neurofibromatosis. J Eur Acad Dermatol Venereol 2008;22:394-395.

24. Mahé E, Zeller J, Wechsler J, Wolkenstein P, Revuz J. [Large hairy pigmented spots in neurofibromatosis type 1: an atypical form of neurofibromas]. Ann Dermatol Venereol 2001;128:619-621. French.

25. Tatemoto K. Neuropeptide $Y$ and its receptor antagonists. Use of an analog mixture-screening strategy. Ann N Y Acad Sci 1990;611:1-6.

26. Pedrazzini T, Pralong F, Grouzmann E. Neuropeptide Y: the universal soldier. Cell Mol Life Sci 2003;60:350-377.

27. Scheenen WJ, Jenks BG, Willems PH, Roubos EW. Action of stimulatory and inhibitory alpha-MSH secretagogues on spontaneous calcium oscillations in melanotrope cells of Xenopus laevis. Pflugers Arch 1994;427:244-251.

28. Weihe E, Hartschuh W. Multiple peptides in cutaneous 
nerves: regulators under physiological conditions and a pathogenetic role in skin disease? Semin Dermatol 1988;7: 284-300

29. Takahashi K, Nakanishi S, Imamura S. Direct effects of cutaneous neuropeptides on adenylyl cyclase activity and proliferation in a keratinocyte cell line: stimulation of cyclic AMP formation by CGRP and VIP/PHM, and inhibition by NPY through G protein-coupled receptors. J Invest Dermatol 1993;101:646-651.

30. Berger A, Santic R, Hauser-Kronberger C, Schilling FH, Kogner $\mathrm{P}$, Ratschek $\mathrm{M}$, et al. Galanin and galanin receptors in human cancers. Neuropeptides 2005;39:353-359.

31. Grenbäck E, Bjellerup P, Wallerman E, Lundblad L, Anggård A, Ericson K, et al. Galanin in pituitary adenomas. Regul Pept 2004;117:127-139.

32. Kofler B, Berger A, Santic R, Moritz K, Almer D, Tuechler $C$, et al. Expression of neuropeptide galanin and galanin receptors in human skin. J Invest Dermatol 2004;122:10501053.

33. Hafner C, Stempfl T, Bäumler W, Hohenleutner U, Landthaler M, Vogt T. Gene expression profiling of melanocytes following Q-Switched Ruby laser irradiation. Dermatology 2008;216:6-13.

34. Dallos A, Kiss M, Polyánka H, Dobozy A, Kemény L, Husz $\mathrm{S}$. Galanin receptor expression in cultured human keratinocytes and in normal human skin. J Peripher Nerv Syst 2006;11:156-164.

35. Ji RR, Zhang X, Zhang Q, Dagerlind A, Nilsson S, Wiesenfeld-Hallin Z, et al. Central and peripheral expression of galanin in response to inflammation. Neuroscience 1995; 68:563-576.

36. Carraway R, Leeman SE. The isolation of a new hypotensive peptide, neurotensin, from bovine hypothalami. J Biol Chem 1973;248:6854-6861.

37. Dupouy S, Mourra N, Doan VK, Gompel A, Alifano M, Forgez $\mathrm{P}$. The potential use of the neurotensin high affinity receptor 1 as a biomarker for cancer progression and as a component of personalized medicine in selective cancers. Biochimie 2011;93:1369-1378.

38. Theoharides TC, Stewart JM, Taracanova A, Conti P, Zouboulis CC. Neuroendocrinology of the skin. Rev Endocr Metab Disord 2016;17:287-294.

39. Alysandratos KD, Asadi S, Angelidou A, Zhang B, Sismanopoulos $\mathrm{N}$, Yang $\mathrm{H}$, et al. Neurotensin and $\mathrm{CRH}$ interactions augment human mast cell activation. PLoS One 2012;7:e48934.

40. Muallem MM, Rubeiz NG. Physiological and biological skin changes in pregnancy. Clin Dermatol 2006;24:80-83.

41. Peters EM, Ericson ME, Hosoi J, Seiffert K, Hordinsky MK, Ansel JC, et al. Neuropeptide control mechanisms in cutaneous biology: physiological and clinical significance. J Invest Dermatol 2006;126:1937-1947.

42. Nordlund JJ. Postinflammatory hyperpigmentation. Dermatol Clin 1988;6:185-192.

43. Maimone D, Cioni C, Rosa S, Macchia G, Aloisi F, Annunziata $\mathrm{P}$. Norepinephrine and vasoactive intestinal peptide induce IL-6 secretion by astrocytes: synergism with IL-1 beta and TNF alpha. J Neuroimmunol 1993;47:73-81.

44. Gottschall PE, Tatsuno I, Arimura A. Regulation of interleukin-6 (IL-6) secretion in primary cultured rat astrocytes: synergism of interleukin-1 (IL-1) and pituitary adenylate cyclase activating polypeptide (PACAP). Brain Res 1994; 637:197-203. 